\title{
Impact of Monthly Curve Number on Daily Runoff Estimation for Ozat Catchment in India
}

\author{
Manoj Gundalia', Mrugen Dholakia² \\ ${ }^{1}$ Department of Civil Engineering, Dr. Subhash Technical Campus, Junagadh, India \\ ${ }^{2}$ Lalbhai Dalpatbhai College of Engineering, Ahmedabad, India \\ Email: mjgundalia@gmail.com
}

Received 7 August 2014; revised 9 September 2014; accepted 7 October 2014

Copyright (C) 2014 by authors and Scientific Research Publishing Inc.

This work is licensed under the Creative Commons Attribution International License (CC BY). http://creativecommons.org/licenses/by/4.0/

(c) (i) Open Access

\section{Abstract}

The Soil Conservation Service Curve Number (SCS-CN) is a well-established loss-rate model to estimate runoff. It combines watershed parameters and climatic factors in one entity curve number $(C N)$. The $C N$ exhibits an inherent seasonality beyond its spatial variability, which cannot be accounted for by the conventional methods. In the present study, an attempt has been made to determine the $C N$ for different months of monsoon season with an objective to evaluate the impact of monthly $C N$ on runoff estimation for Ozat catchment (Gujarat State, India). The standard $C N$ and month wise $C N$ were determined by three procedures, viz, the median, geometric mean and standard asymptotic fit using gauged rainfall and runoff. This study shows that the predictive capability of $C N$ determination methods can be improved by using monthly $C N$. Refined Willmott's index ( $d_{r}$ ) and mean absolute error (MAE) were used to assess and validate the performance of each method. The asymptotic fit $C N$ method with monthly $C N$ resulting $d_{r}$ from 0.46 to 0.49 and MAE from $1.13 \mathrm{~mm}$ to $1.18 \mathrm{~mm}$ was judged to be more consistent with the existing commonly used $C N$ methods in terms of runoff estimation for the study area.

\section{Keywords}

Soil Conservation Service Curve Number (SCS-CN) Method, CN Variation, Seasonal Effect, Ozat Catchment

\section{Introduction}

The Natural Resources Conservation Service (NRCS) curve number $(C N)$ procedure is widely used to estimate 
runoff resulting from rainfall. The primary reason for its wide applicability and acceptability lies in the fact that it accounts for major runoff-generating watershed characteristics, namely, soil type, land use/treatment, surface condition and antecedent moisture condition [1]-[3]. In contrast, the main weaknesses reported in the literature are that the SCS-CN method does not consider the impact of rainfall intensity; it does not address the effects of spatial scale. It is highly sensitive to changes in values of its single parameter $C N$, and it is ambiguous considering the effect of antecedent moisture conditions [4]-[6]. Nevertheless, the model development has made much progress in last three decades; a need of further improvements has always been experienced to satisfy unresolved challenges.

After the critical examination of the methodology, the SCS-CN method has gained much attention with respect to its modification and investigation. Subsequent studies (e.g. [7]-[10]) examine the accuracy of the curve number method and identify specific weaknesses and limitations that are not widely recognized and that are rarely noted in textbooks. Recent modifications in determination of $C N$ are reported by slope adjustment procedure [11], two-CN system approach [12] and composite CN-generation [13]. The SCS-CN model implementing with these modifications would have a better simulation performance than the existing original SCS-CN. In $C N$ method, parameters which influence the seasonal variation on predicting runoff have not been incorporated and hence they ignore the impact of seasonal and monthly variation. Although the $C N$ method is well documented and widely used, as [14] pointed out, a need to use the method as a guideline and to interpret inputs on a more local and regional level combined with seasonal variation was essential. Runoff simulation with annually consistent parameters has limited application because watershed response varies remarkably from season to season. The seasonal tank model developed by [15] showed better performance compared with the non-seasonal tank model because it can successfully simulate runoff with little error. $C N$ on monthly basis, therefore, may also result in more accurate runoff estimation and improve the $C N$ performance. The investigation reported in this paper is motivated by the need to evaluate the impact of monthly variation on the $C N$ and its influence on runoff estimation for Ozat catchment.

The objectives of this study were 1) to assess the applicability of $C N$ s determination procedures including the median, geometric mean [16] and standard asymptotic fit [17] in estimating runoff; 2) to evaluate the impact of the performance of monthly $C N$ in prediction of runoff volume for Ozat watershed.

\section{Materials and Methodology}

\subsection{Study Ares and Data Collection}

Ozat is a river flowing in western India in Gujarat state whose origin is near Visavadar and meets in Arebian Sea. Ozat catchment considered in this study geographically locates within the latitudes $21^{\circ} 19^{\prime} \mathrm{N}$ to $21^{\circ} 33^{\prime} \mathrm{N}$ and the longitudes $70^{\circ} 39^{\prime} \mathrm{E}$ to $70^{\circ} 56^{\prime} \mathrm{E}$ respectively as can be seen from toposheet no $41 \mathrm{~K}$ (10-11-14 and 15) of scale 1:50000. The gauge discharge site is located near Khambhaliya village at bridge of Junagadh to Visavadar Road $33 \mathrm{~km}$ away from Junagadh. Information about soil and land use have been gathered from maps of National Bureau of Soil Survey and Land use Planning (ICAR) (1994). Study area (sub-watershed) has been delineated from Survey of India (SOI) topographic sheet using AutoCAD (2010) Software in Figure 1. The major portion of the precipitation occurs during the four months of June to September by south-west monsoon. The area is situated in semi-arid region with average annual rainfall of the area is $786 \mathrm{~mm}$ (1980-2010), mean maximum temperature $33.34^{\circ} \mathrm{C}$ and mean minimum temperature $24.30^{\circ} \mathrm{C}$. The total geographical area $358.8357 \mathrm{~km}^{2}$ comprises of about $20.08 \%\left(72.0542 \mathrm{~km}^{2}\right)$ grass and open scrub land and remaining $79.92 \%$ area under arable land irrigated $\left(286.7815 \mathrm{~km}^{2}\right)$. The major crops grown in the catchment are Ground nut, wheat and Cotton.

The hydrological data daily rainfall $(\mathrm{mm})$ and runoff $\left(\mathrm{m}^{3} / \mathrm{s}\right)(1980$ to 2010$)$ and meteorological data daily maximum and minimum temperatures of Ozat catchment were collected from the State Water Data Centre, Gandhinagar. The information related to watershed characteristics, namely, physiography, number of streams of different orders, their length, slope and area contributing runoff to these streams were obtained from the topographic maps of the watershed.

Periodic insufficient rainfall pattern, limited water storage capacity of aquifer and natural water conservation are vital issues for this region. Water availability is a critical factor in this area and therefore accurate estimation of runoff is needed for water resources management, crop water use, farm irrigation scheduling, and environmental assessment. 


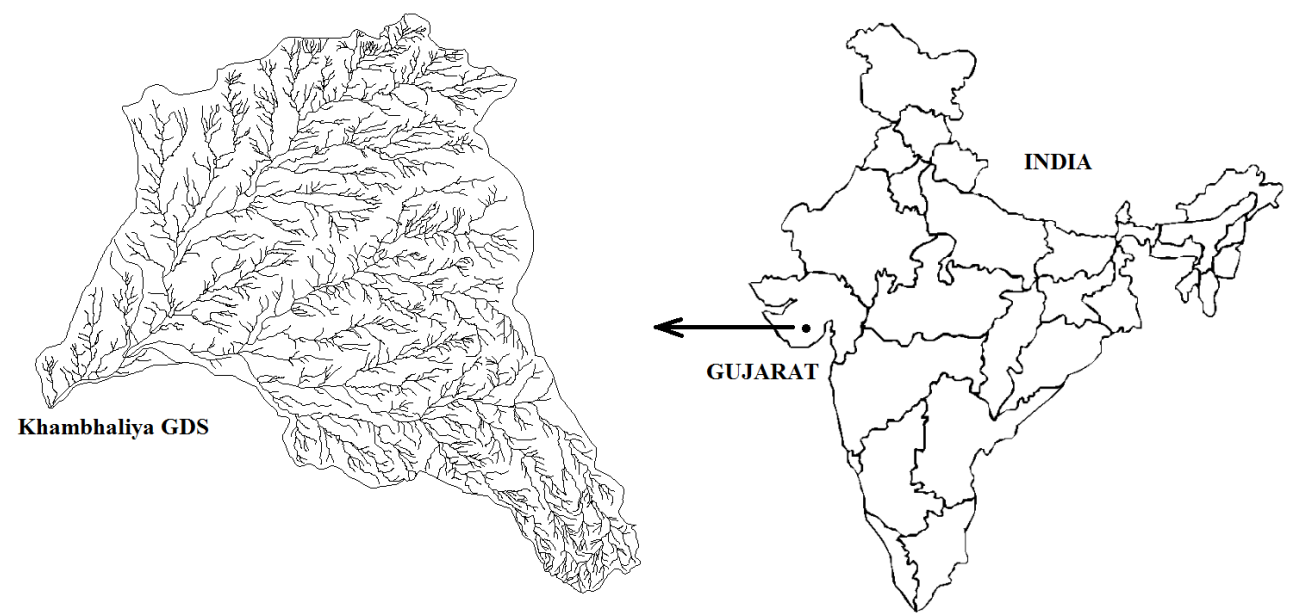

Figure 1. Digitized 6th order drainage network map of Ozat catchment.

\subsection{SCS-CN Method}

One of the most commonly used methods to estimate the volume of surface runoff for a given rainfall event is the (SCS-CN) method [18], which has been now renamed as (NRCS-CN) method. The SCS-CN method is based on the principle of the water balance and two fundamental hypotheses. The first hypothesis states that the ratio of direct runoff to potential maximum runoff is equal to the ratio of infiltration to potential maximum retention. The second hypothesis states that the initial abstraction is proportional to the potential maximum retention. The water balance equation and the two hypotheses are expressed mathematically respectively, as:

$$
\begin{gathered}
P=I_{a}+F+Q \\
\frac{Q}{P-I_{a}}=\frac{F}{S} \\
I_{a}=\lambda S
\end{gathered}
$$

where $P$ is the total precipitation $(\mathrm{mm}), I_{a}$ is the initial abstraction before runoff $(\mathrm{mm}), F$ is the cumulative infiltration after runoff begins $(\mathrm{mm}), Q$ is direct runoff $(\mathrm{mm}), S$ is the potential maximum retention $(\mathrm{mm})$, and $\lambda$ is the initial abstraction (ratio) coefficient.

Small amount of rainfall events result in even smaller changes in runoff that can sometimes be difficult to discern in the discharge time series. To minimize uncertainty in the determination of the storm event discharge, storms events with $P \geq 5 \mathrm{~mm}$ have been considered to determine $C N$ values in calibration period for this study. In validation period all events have been considered to measure performance of different procedures.

$\lambda=0.2$ was assumed in original SCS-CN model. But, this assumption has often been questioned for its rationality and applicability, invoking a critical examination of the $I_{a}-S$ relationship for practical applications [19]. A study using rainfall and runoff data from 307 US catchments or plots found that a value of $\lambda=0.05$ would fit the data much better [20]. [21] found that the prediction accuracy for $\lambda=0.05$ was greater than that for $\lambda=0.2$ using SCS-CN method to simulate plot runoff of 757 rainfall events in Zizhou and Xifeng cities located in the Loess Plateau of China. Similar results have been obtained from plots or watersheds in USA [22], semi-arid tropical highlands of Northern Ethiopia [23] and the Three Gorges area of China [24]. The assumption $\lambda=0.20$ has been recently considered unusually high and recent studies [25]-[27] suggested the use of $\lambda=0.05$. In the present study performance of all the methods were compared and tested with $\lambda=0.05, \lambda=0.1$ and $\lambda=0.2$ in validation.

The general runoff equation combination of Equation (1) and Equation (2) is shown in Equation (4):

$$
\begin{aligned}
Q & =\frac{\left(P-I_{a}\right)^{2}}{P-I_{a}+S} \text { for } P>I_{a} \\
& =0 \text { otherwise }
\end{aligned}
$$

The potential maximum retention $S(\mathrm{~mm})$ can vary in the range of $0 \leq S \leq \infty$, and it directly linked to $C N$. Pa- 
rameter $S$ is mapped to the $C N$ using Equation (4) as:

$$
S=\frac{25400}{C N}-254
$$

The $C N$ depends on land use, hydrologic soil group, hydrologic condition, antecedent moisture condition (AMC) and it can vary from 0 to 100 . Three AMCs were defined as dry (lower limit of moisture or upper limit of $S$ ), moderate (normal or average soil moisture condition), and wet (upper limit of moisture or lower limit of S), and denoted as AMC I, AMC II, and AMC III, respectively [28]. Higher amount of antecedent moisture and $C N$ value would indicate the high runoff and vice versa, therefore, median $C N$ computed from array of $C N$ values and was commonly adopted for the catchment [29].

Normally variations in storm characteristics and surface conditions can responsible for variation in $C N$ between events. Possible sources of $C N$ variability may be the effect of the temporal and spatial variability of storm and watershed properties, the quality of the measured data, and the effect of antecedent rainfall and associated soil moisture. [30] [31] also noted that the variation of $C N$ value, according to AMC category alone, cannot justify the observed $C N$ values variability in every case. Much of the variability in $C N$ has been attributed to antecedent runoff content (ARC) such that soils that are wetter have a higher curve number, creating more runoff for a given amount of precipitation, than soils that are drier [32] [33]. Many researchers have demonstrated from rainfall and runoff data that its key parameter $C N$ has variable components and is not a constant for a watershed [34], and varies with rainfall. A parameter that exhibits seasonal variation on forecasting runoff volume has not been incorporated in the $C N$ method and as a result ignores the impact of seasonal and monthly variation on evaporation, transpiration and interception. Therefore, monthly $C N$ may play significant role in runoff estimation. A previous study [35] analyses the Variability of annual and seasonal curve number in Bamhani, Manot, Mohgaon and Shakkar watersheds of Narmada basin. They concluded that monthly $C N$ indicates a homogeneous pattern of variation in all the four watersheds in the basin. Based on this previous work, we evaluated the performance of the median, geometric mean, and standard asymptotic fit procedures using monthly $C N$.

\subsection{Curve Number Estimation}

The $C N$ values corresponding to the catchment soil types, land cover and land management conditions can be selected from the NEH-4 tables. The $C N$ value of AMC II (CNII) was provided by the SCS-CN manual and the $C N$ value of AMC I (CNI) and $C N$ value of AMC III (CNIII) can be calculated by applying the [36] equations. $C N \mathrm{I}, C N \mathrm{II}$ and $C N \mathrm{III}$ values for Ozat catchment were computed 64.46, 81.20 and 90.85 respectively based on land used, soil characteristics and previous 5-day rainfall of the catchment.

In this study $C N$ s were determined by three different methods using gauged rainfall and runoff. These methods include the median, geometric mean, and standard asymptotic fit. When rainfall-runoff data are available for a watershed, $P$ and $Q$ pairs are used directly to determine the potential retention $S$ characterizing the watershed [37] as:

$$
S=\frac{P}{\lambda}+\frac{(1-\lambda) Q-\sqrt{(1-\lambda)^{2} Q^{2}+4 \lambda P Q}}{2 \lambda^{2}}
$$

$C N$ value can be directly calculated from rainfall-runoff data by substituting value of $S$ in Equation (5) and rearranging it as:

$$
C N=\frac{25400}{\frac{P}{\lambda}+\frac{(1-\lambda) Q-\sqrt{(1-\lambda)^{2} Q^{2}+4 \lambda P Q}}{2 \lambda^{2}}}+254
$$

The median $C N$ was computed by finding the median of the $C N \mathrm{~s}$ of selected events from the calibration period (1980-1994). The $C N$ s for events were computed using Equation (6) and Equation (7). The median $C N$ as calculated from rainfall and runoff depths associated with the daily runoff events appears to have been the source of the original handbook table values. This procedure has the benefits of simplicity, precedent, and consistency with existing tables. However, it requires long records (one observation per year) and is incapable of capturing short term or transient effects, such as a fire or changes in agronomic practices [38].

The geometric mean has been used to determine a watershed $C N$ if the values calculated from rainfall and ru- 
noff measured for each event are log normally distributed [39]. Yet, no one seems to have established the lognormality of $C N$ distributions. The major strength of the geometric mean is quantification of uncertainty with the standard deviation and confidence intervals. The normal distribution describes many random processes but it generally does not provide satisfactory fit for flood discharge and other hydrologic data. Though, the normal distribution is not well suited to hydrologic data, the related distribution; the lognormal distribution works reasonably well [40]. The geometric mean is obtained by finding the arithmetic mean of the series $\overline{\log S}$; and then estimating the geometric mean maximum potential retention $10^{\frac{\log S}{2}}$. The $C N$ is then computed using Equation (8):

$$
C N=\frac{100 \alpha}{\alpha+10^{\overline{\log S}}}
$$

where $\alpha=254 \mathrm{~mm}$ (10 in).

In standard asymptotic fit method (AFM), $P$ and $Q$ data are re-aligned on a rank-order basis, creating a new set of $P: Q$ pairs (ordered $P: Q$ data). This is done by rank ordering the rainfalls and runoff separately, and reassembling them as rank-ordered pairs. The Standard response was observed in Ozat catchment and to be described by the following:

$$
C N(P)=C N_{\infty}+\left(100-C N_{\infty}\right) e^{-k P}
$$

Equation (9) has the algebraic structure of the Horton infiltration equation. In the standard response, the $C N$ as a function of rainfall $P(C N[P])$ decreases to an asymptotic constant $C N_{\infty}$ with $k$ (the fitting coefficient or rate constant in the units of $1 / P$ ) that describes the $C N$ approach to the asymptotic constant $C N_{\infty}$. Optimized values of $C N_{\infty}$ and $k$ are obtained by fitting Equation (9) using least-squares procedure. The recent report to NRCS [41] recommends this procedure as the preferred technique for $C N$ parameterization.

\subsection{Monthly Curve Number}

The mean monthly $C N$ s of fifteen years period (1980-1994) were calculated using median method and geometric mean method. The highest values of $C N$ were recorded in September month while the lowest values were recorded in the month of October. In (AFM) method, month wise optimized values of parameters $C N_{\infty}$ and $k$ were computed using ordered $P: Q$ data. $C N \mathrm{~s}$ values were then determined by incorporating mean monthly rainfall amount of calibration period (1980-1994), $C N_{\infty}$ and $k$ in Equation (9). Variations in $C N$ with rainfall $P$ for each month of monsoon season are presented in Figures 2-6 with parameters $C N_{\infty}$ and $k$ values. Table 1 presents estimated monthly $C N$ values by all three procedures with mean monthly rainfall. Month wise optimal values of parameters $C N_{\infty}$ and $k$ during monsoon season are also presented in Table 1 for Ozat catchment.

In stream flow separation, the most frequently used methods are filtering separation method and statistical method (Frequency-Duration analysis). In filtering separation method, base flow separates from the stream flow time series data by processing or filtering procedure. Although these methods don't have any physical basis it aims at generating an objective, repeatable and easily automated index that can be related to the base flow response of the catchment [42]. In this study the [43] filtering method is used to separate base flow from stream flow.

$$
Q_{d(i)}=\alpha Q_{d(i-1)}+\beta(1+\alpha)\left(Q_{T(i)}-Q_{T(i-1)}\right)
$$

where,

$Q_{d}=$ direct flow part of the stream flow which is subjected to $Q_{d} \geq 0$ for the time $i$ in days;

$Q_{T}=$ total flow (i.e. base flow + direct flow);

$\alpha=$ a coefficient with value 0.925 ;

$\beta=$ a coefficient with value 0.5 .

\section{Statistical Criteria}

In this study, the performance of three $C N$ determination procedures, viz, the median, geometric mean and standard asymptotic fit with standard $C N$ and monthly $C N$ are evaluated using two popular statistical criteria refined Willmott's index $\left(\mathrm{d}_{\mathrm{r}}\right)$ [44] (Dimensionless statistic) and mean absolute error (MAE) (error index statistic). Dimensionless techniques provide a relative model evaluation assessment, and error indices quantify the deviation 
Table 1. Month wise $C N, C N_{\infty}$ and $K$ for different procedures.

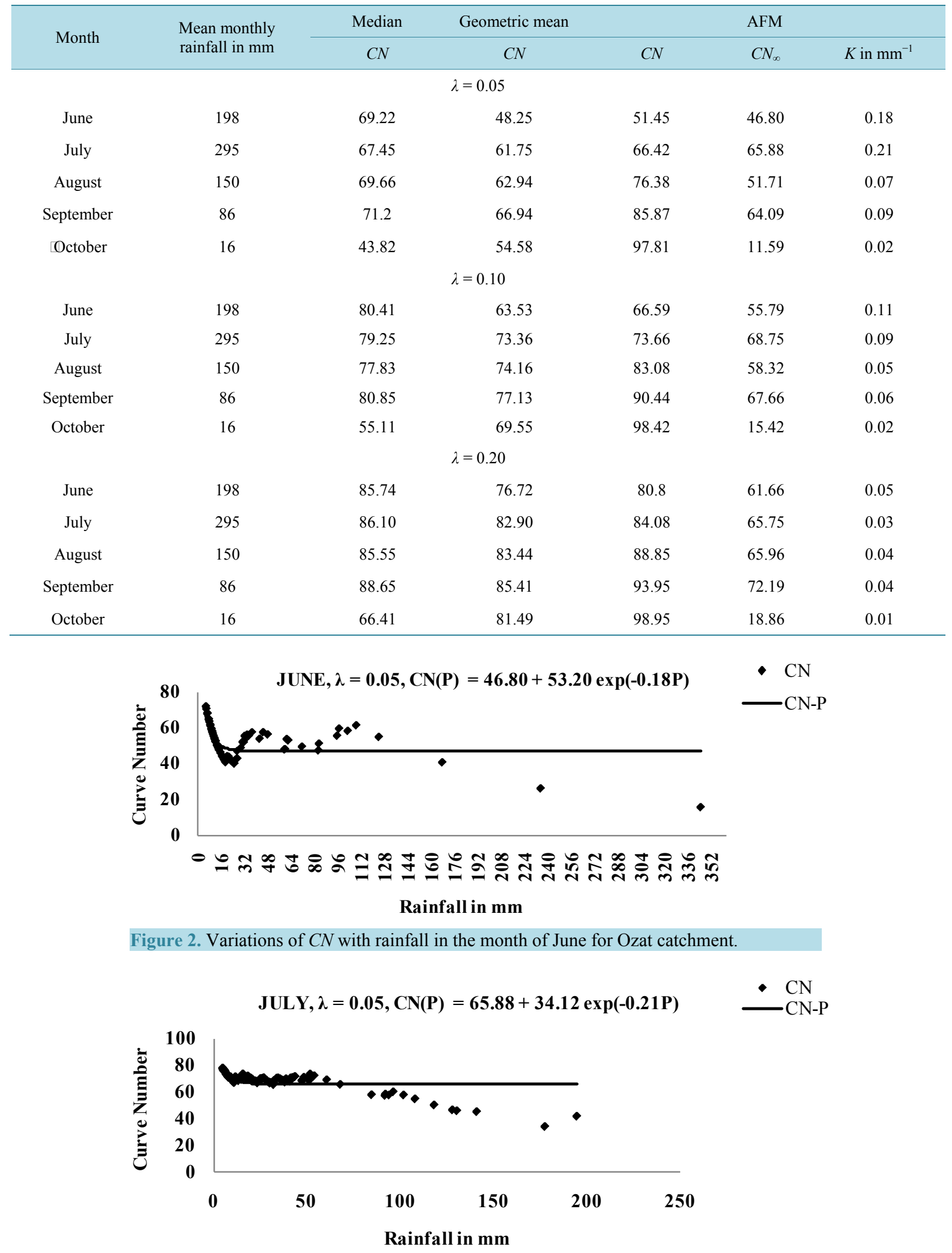

Figure 3. Variations of $C N$ with rainfall in the month of July for Ozat catchment. 


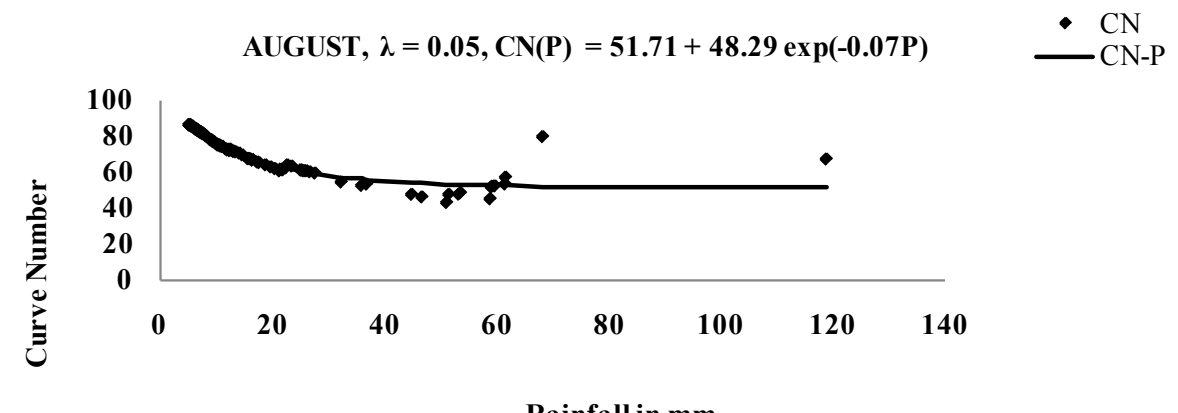

Rainfall in mm

Figure 4. Variations of $C N$ with rainfall in the month of August for Ozat catchment.

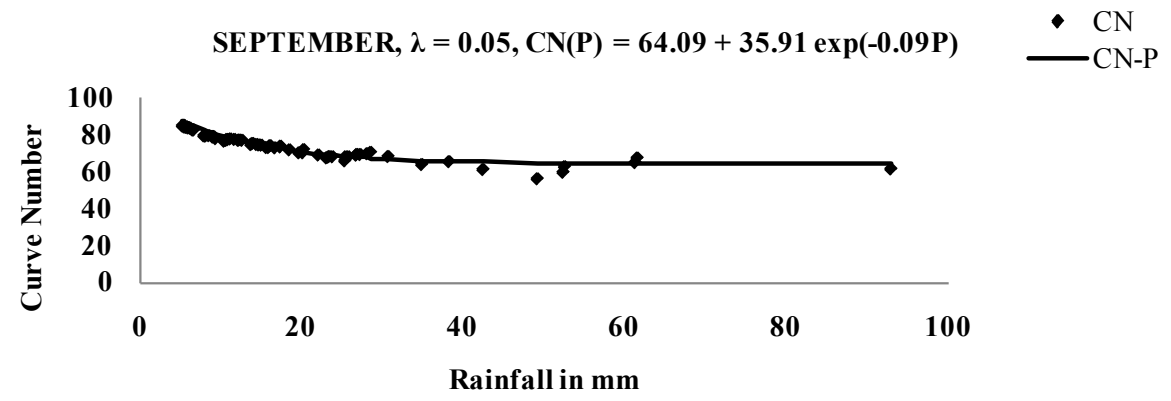

Figure 5. Variations of $C N$ with rainfall in the month of September for Ozat catchment.

OCTOBER MONTH, $\lambda=0.05, \mathrm{CN}(\mathrm{P})=11.59+88.41 \exp (-0.02 \mathrm{P})$

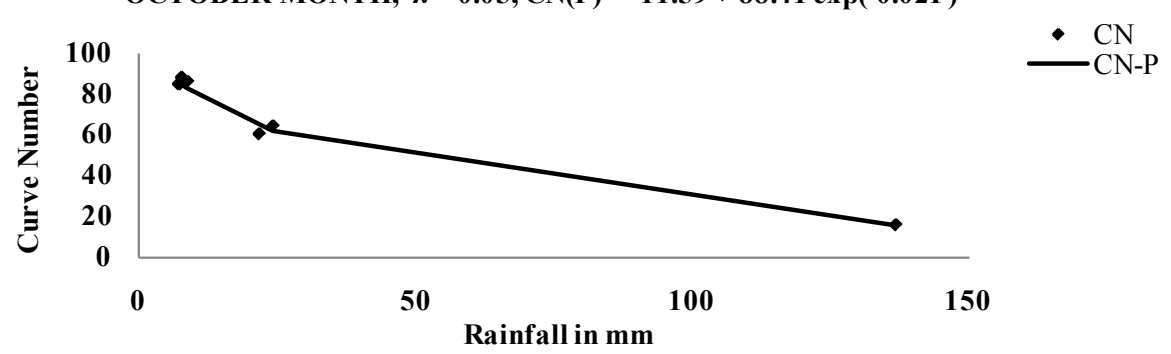

Figure 6. Variations of $C N$ with rainfall in the month of October for Ozat catchment.

in the units of the data of interest. These statistical criteria are used to measure the agreement between predicted and observed values of event runoff in validation period (1995-2010). To check precision and correctness of the methods, $\left(d_{r}\right)$ is applied. The MAE does not tell about degree of error but it is used for the quantitative analysis of residuals.

The $\mathrm{d}_{\mathrm{r}}$ is applied to quantify the degree to which values of observed runoff are captured by the models. The range of $d_{r}$ is from -1.0 to 1.0. A $d_{r}$ of 1.0 indicates perfect agreement between model and observation, and a $d_{r}$ of -1.0 indicates either lack of agreement between the model and observation or insufficient variation in observations to adequately test the model.

MAE is error measure used to represent the average difference between model predicted and observed values. It is important to include absolute error measures MAE in a model evaluation because it provides an estimate of model error in the units of the variable. The MAE provides a more robust measure of average model error than the root mean square error (RMSE), since it is not influenced by extreme outliers [45]. A higher MAE value indicates poor model performance and vice versa. $\mathrm{MAE}=0$ indicates a perfect fit. MAE is the most natural and unambiguous measure of average error magnitude.

All the three procedures with standard $C N$ and monthly $C N$ values, considered for the present study, have been applied to estimate runoff for the Ozat catchment. The resulting values of $d_{r}$, and MAE are presented in Table 2. 
Table 2. Performance of different procedures in validation.

\begin{tabular}{|c|c|c|c|c|c|c|}
\hline \multicolumn{7}{|c|}{ With standard $C N$ values } \\
\hline & \multicolumn{2}{|c|}{ Median $C N$} & \multicolumn{2}{|c|}{ Geometric mean $C N$} & \multicolumn{2}{|c|}{ AFM $C N$} \\
\hline$\lambda$ & $\mathrm{d}_{\mathrm{r}}$ & MAE in mm & $\mathrm{d}_{\mathrm{r}}$ & MAE in mm & $\mathrm{d}_{\mathrm{r}}$ & MAE in $\mathrm{mm}$ \\
\hline 0.05 & 0.27 & 1.47 & 0.37 & 1.24 & 0.47 & 1.18 \\
\hline 0.10 & 0.15 & 1.68 & 0.27 & 1.44 & 0.48 & 1.16 \\
\hline 0.20 & 0.04 & 1.89 & 0.14 & 1.8 & 0.49 & 1.13 \\
\hline \multicolumn{7}{|c|}{ With monthly $C N$ values } \\
\hline & \multicolumn{2}{|c|}{ Median $C N$} & \multicolumn{2}{|c|}{ Geometric mean $C N$} & \multicolumn{2}{|c|}{ AFM $C N$} \\
\hline$\lambda$ & $d_{r}$ & MAE in mm & $\mathrm{d}_{\mathrm{r}}$ & MAE in mm & $\mathrm{d}_{\mathrm{r}}$ & MAE in $\mathrm{mm}$ \\
\hline 0.05 & 0.29 & 1.41 & 0.40 & 1.18 & 0.47 & 1.16 \\
\hline 0.10 & 0.15 & 1.70 & 0.29 & 1.38 & 0.46 & 1.17 \\
\hline 0.20 & 0.02 & 1.92 & 0.15 & 1.65 & 0.48 & 1.13 \\
\hline
\end{tabular}

\section{Results and Discussion}

The median, geometric mean and standard asymptotic fit procedures are applied with standard $C N$ and monthly $C N$ on the data set of Ozat catchment. The data set of 15 years (1980-1994) was used to determine standard $C N$ and monthly $C N$ for each procedure and the data set of 16 years (1995-2010) was used for validation. The results of the performances of these methods are presented in Table 2. Performances of these methods on monthly time scale in validation period are shown in Figures 7-9.

It is evident from Table 1 that estimated $C N$ values have direct relationship with $\lambda$. Median $C N \mathrm{~s}$ are found in range from 43.82 to 88.65 , geometric $C N \mathrm{~s}$ in range from 48.25 to 85.41 and $A F M C N \mathrm{~s}$ in range from 51.45 to 98.95. Median and geometric mean procedures are estimated the highest $C N$ values for $\lambda=0.20$ in the month of September and the lowest $C N$ value for $\lambda=0.05$ in the month of October. Median procedure estimated higher $C N$ values than geometric mean procedure except in October month. Sudden drop found in $C N \mathrm{~s}$ values from September to October month in median and geometric mean procedures which may be due to very little rainfall in October month. More than $98 \%$ precipitation occurs from June to September in Ozat catchment. $C N$ s values increased gradually with $\lambda$ from June to October in AFM method. Optimized values of parameter $C N_{\infty}$ are increased while optimized values of parameter $k$ are decreased with increment in $\lambda . C N_{\infty}$ values exhibited inverse relationship with $k$ values. The highest value of $C N_{\infty}$ is estimated in September month within range of 64.09 to 72.19 while lowest value is found in the month of October within range of 11.59 to 15.42 . The values of $k$ decrease from 0.21 to 0.01 with increment in the $\lambda$ from 0.05 to 0.20 , it is also evident that a value of $k$ is the lowest in the month of October.

The AFM procedure is provided comparatively more realistic results with $\mathrm{d}_{\mathrm{r}}=0.49$ and MAE $=1.13 \mathrm{~mm}$ for $\lambda$ $=0.20$. As compare to AFM method, other two methods are shown poor performance in goodness of fit criteria and produced the results with marginally larger errors. Substantial improvement in error estimate is noticed while using monthly $C N$ values replacing standard $C N$ values. For $\lambda=0.05$, all three methods had a good performance in predicting the daily runoff with monthly $C N$ values for the study area. These results are in good agreement to the previous studies.

\section{Summary and Conclusions}

The median, geometric mean and asymptotic fit procedures for $C N$ determination are applied and evaluated with standard $C N$ values and monthly $C N$ values to estimate runoff for Ozat catchment of India.

The following conclusions can be drawn from this study:

1) The performance of the SCS-CN method is improved on application of monthly $C N$.

2) The $C N$ values increase with increment in $\lambda$ from 0.05 to 0.20 .

3) The $C N$ values computed from median procedure are higher than $C N$ values computed from geometric mean procedure.

4) All the methods perform well with $\lambda=0.05$ for Ozat catchment. 


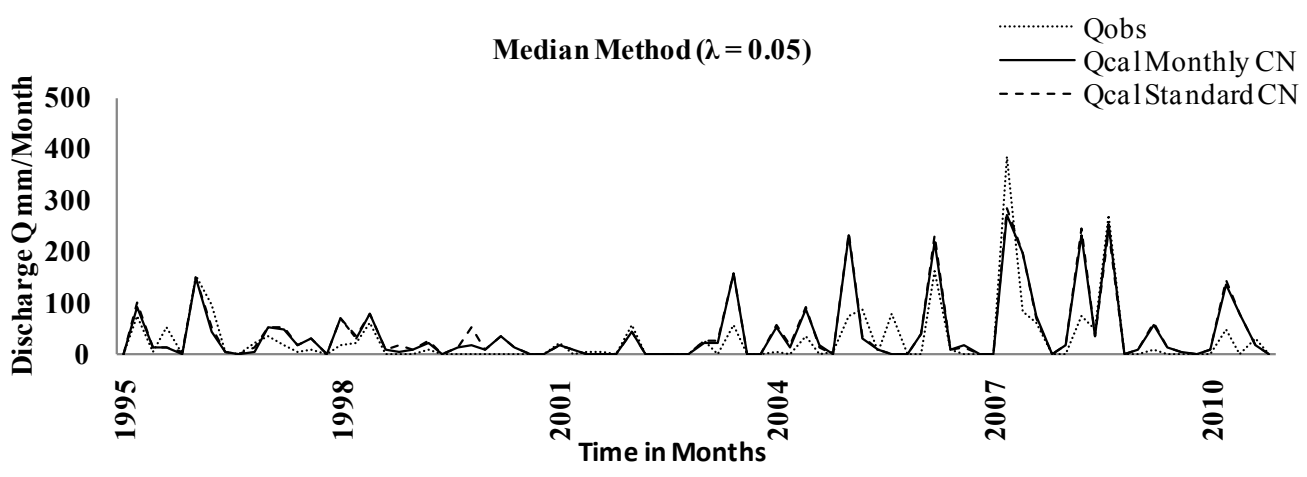

Figure 7. Performance of median $C N$ and median monthly $C N$ on monthly time scale in validation.

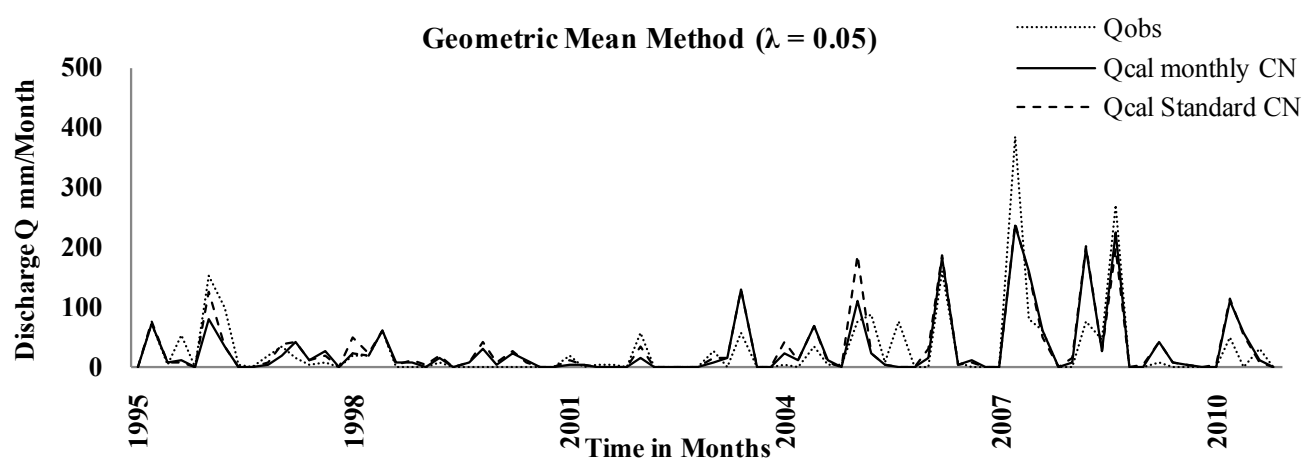

Figure 8. Performance of geometric mean $C N$ and geometric mean monthly $C N$ on monthly time scale in validation.

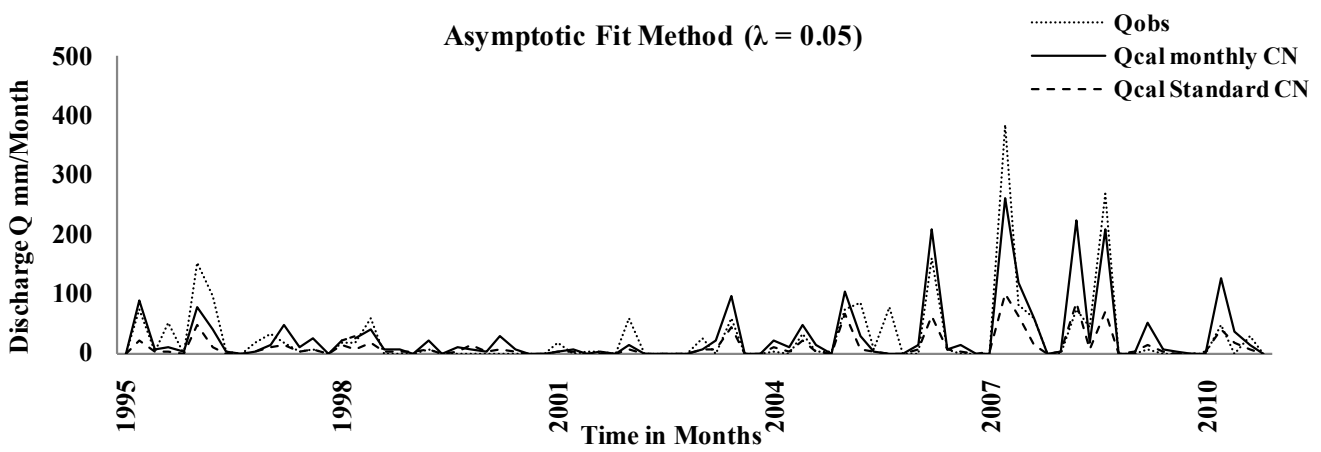

Figure 9. Performance of AFM $C N$ and AFM monthly $C N$ on monthly time scale in validation.

5) The highest $C N$ values are found in the month of September and the lowest $C N$ values are found in the month of October for median and geometric mean methods.

6) Asymptotic $C N$ parameters $\left(C N_{\infty}\right)$ increase with $\lambda$ and attain the highest value in September.

7) Inverse relationship is observed between $\lambda$ and fitting parameter $k$.

8) The lowest values of parameters $C N_{\infty}$ and $k$ are found in October.

Considering above all the results, we conclude that the relatively best performance is observed by the AFM method with higher $d_{r}$ values and lower MAE values. This study shows that the predictive capability of $C N$ determination methods can be improved by the use of monthly $C N$ values replacing standard $C N$ values for the Ozat catchment.

\section{Acknowledgements}

The authors express sincere thanks to State Water Data Centre, Gandhinagar, for providing daily rainfall and 
runoff data of Khambhaliya Gauge Discharge Site and Divisional Office Junagadh (Irrigation Department), Gujarat for supplying us different maps of the study area.

\section{References}

[1] Mishra, S.K. and Singh, V.P. (2002) SCS-CN-Based Hydrologic Simulation Package. In: Singh, V.P. and Frevert, D.K., Eds., Mathematical Models in Small Watershed Hydrology and Applications, Water Resources Publications, Littleton, 391-464.

[2] Mishra, S.K. and Singh, V.P. (2003) Soil Conservation Service Curve Number (SCS-CN) Methodology. Kluwer Academic Publishers, Dordrecht. http://dx.doi.org/10.1007/978-94-017-0147-1

[3] Ponce, V.M. and Hawkins, R.H. (1996) Runoff Curve Number: Has It Reached Maturity? Journal of Hydrologic Engineering (ASCE), 1, 11-19.

[4] Michel, C., Andréassian, V. and Perrin, C. (2005) Soil Conservation Service Curve Number Method: How to Mend a Wrong Soil Moisture Accounting Procedure? Water Resources Research, 41, 1-6. http://dx.doi.org/10.1029/2004WR003191

[5] Hawkins, R.H. (1993) Asymptotic Determination of Runoff Curve Numbers from Data. Journal of Irrigation and Drainage Engineering, 119, 334-345.

[6] McCuen, R.H. (2002) Approach to Confidence Interval Estimation for Curve Numbers. Journal of Hydrologic Engineering, 7, 43-48. http://dx.doi.org/10.1061/(ASCE)1084-0699(2002)7:1(43)

[7] Garen, D.C. and Moore, D.S. (2005) Curve Number Hydrology in Water Quality Modeling: Uses, Abuses, and Future Directions. Journal of the American Water Resources Association, 41, 377-388. http://dx.doi.org/10.1111/j.1752-1688.2005.tb03742.x

[8] Jacobs, J.M., Myers, D.A. and Whitfield, B.M. (2003) Improved Rainfall/Runoff Estimates Using Remotely Sensed Soil Moisture. Journal of the American Water Resources Association, 39, 313-324. http://dx.doi.org/10.1111/j.1752-1688.2003.tb04386.x

[9] King, K.W., Arnold, J.G. and Bingner, R.L. (1990) Comparison of Green-Ampt and Curve Number Methods on Goodwin Creek Watershed Using SWAT. Transactions of the ASABE, 42, 919-925. http://dx.doi.org/10.13031/2013.13272

[10] McCutcheon, S.C. (2006) Rainfall-Runoff Relationships for Selected Eastern USA Forested Mountain Watersheds: Testing of the Curve Number Method for Flood Analysis. West Virginia Division of Forestry, Charleston.

[11] Sharpley, A.N. and Williams, J.R. (1990) EPIC Erosion/Productivity Impact Calculator: 1. Model Documentation. USA Department of Agriculture Technical Bulletin No. 1768, USA Government Printing Office, Washington DC.

[12] Soulis, K.X. and Valiantzas, J.D. (2012) SCS-CN Parameter Determination Using Rainfall-Runoff Data in Heterogeneous Watersheds: The Two-CN System Approach. Hydrology and Earth System Sciences, 16, 1001-1015. http://dx.doi.org/10.5194/hess-16-1001-2012

[13] Fan, F.L., Deng, Y.B., Hu, X.F. and Weng, Q.H. (2013) Estimating Composite Curve Number Using an Improved SCS-CN Method with Remotely Sensed Variables in Guangzhou, China. Remote Sensing, 5, 1425-1438. http://dx.doi.org/10.3390/rs5031425

[14] Jacobs, J.H. and Srinivasan, R. (2005) Effects of Curve Number Modification on Runoff Estimation Using WSR-88D Rainfall Data in Texas Watersheds. Journal of Soil and Water Conservation, 60, 274-278.

[15] Paik, K., Kim, J.H., Kim, H.S. and Lee, D.R. (2005) A Conceptual Rainfall-Runoff Model Considering Seasonal Variation. Hydrological Processes, 19, 3837-3850. http://dx.doi.org/10.1002/hyp.5984

[16] National Resources Conservation Service (NRCS) (2001) National Engineering Handbook. Section 4: Hydrology, USA Department of Agriculture, Washington DC.

[17] Sneller, J.A. (1985) Computation of Runoff Curve Numbers for Rangelands from Landsat Data. Technical Report HL852, USA Department of Agriculture, Agricultural Research Service, Hydrology Laboratory, Beltsville.

[18] SCS (1956) In Hydrology, National Engineering of Handbook, Soil Conservation Service. Supplement A, Section 4, Chap. 10, USDA, Washington DC.

[19] Baltas, E.A., Dervos, N.A. and Mimikou, M.A. (2007) Technical Note: Determination of the SCS Initial Abstraction Ratio in an Experimental Watershed in Greece. Hydrology and Earth System Sciences, 11, 1825-1829. http://dx.doi.org/10.5194/hess-11-1825-2007

[20] Woodward, D.E., Hawkins, R.H., Jiang, R., Hjelmfelt, A.T., Van Mullem, J.A. and Quan, Q.D. (2003) Runoff Curve Number Method: Examination of the Initial Abstraction Ratio. Proceeding of the World Water and Environment Resources Congress 2003 and Related Symposia, Philadelphia, 23-26 June 2003. 
[21] Fu, S., Zhang, G., Wang, N. and Luo, L. (2011) Initial Abstraction Ratio in the SCS-CN Method in the Loess Plateau of China. Transactions of the ASABE, 54, 163-169. http://dx.doi.org/10.13031/2013.36271

[22] Hawkins, R.H., Jiang, R., Woodward, D.E., Hjelmfelt, A.T., Van Mullem, J.A. and Quan, Q.D. (2002) Runoff Curve Number Method: Examination of the Initial Abstraction Ratio. Proceedings of the 2nd Federal Interagency Hydrologic Modeling Conference, Las Vegas, 27 June-1 July 2010.

[23] Descheemaeker, K., Posen, J., Borselli, L., Nyssen, J., Raes, D., Haile, M., Muys, B. and Deckers, J. (2008) Runoff Curve Numbers for Steep Hillslopes with Natural Vegetation in Semi-Arid Tropical Highland, Northern Ethiopia. Hydrological Processes, 22, 4097-4105. http://dx.doi.org/10.1002/hyp.7011

[24] Shi, Z.H., Chen, L.D., Fang, N.F., Qin, D.F. and Cai, C.F. (2009) Research on SCS-CN Initial Abstraction Using Rainfall-Runoff Event Analysis in the Three Gorges Area, China. Catena, 77, 1-7.

[25] D'Asaro, F. and Grillone, G. (2012) Empirical Investigation of Curve Number Method Parameters in the Mediterranean Area. Journal of Hydrologic Engineering, 17, 1141-1152.

[26] D'Asaro, F. and Grillone, G. (2010) Runoff Curve Number Method in Sicily: CN Determination and Analysis of the Initial Abstraction Ratio. Proceedings of the 4th Federal Interagency Hydrologic Modeling Conference, Las Vegas, 27 June-1 July 2010, 1-12.

[27] Hawkins, R.H., Ward, T.J., Woodward, D.E. and Van Mullem, J.A. (2009) Curve Number Hydrology: State of the Practice. American Society of Civil Engineers, Reston, $106 \mathrm{p}$.

[28] Mishra, S.K. and Singh, V.P. (2003) Soil Conservation Service Curve Number (SCS-CN) Methodology. Kluwer Academic Publishers, Dordrecht.

[29] Mishra, S.K., Jain, M.K., Pandey, R.P. and Singh, V.P. (2005) Catchment Area Based Evaluation of the AMC-Dependent SCS-CN-Inspired Rainfall-Runoff Models. Hydrological Processes, 19, 2701-2718. http://dx.doi.org/10.1002/hyp.5736

[30] Soulis, K.X., Valiantzas, J.D., Dercas, N. and Londra, P.A. (2009) Investigation of the Direct Runoff Generation Mechanism for the Analysis of the SCS-CN Method Applicability to a Partial Area Experimental Watershed. Hydrology and Earth System Sciences, 13, 605-615. http://dx.doi.org/10.5194/hess-13-605-2009

[31] Steenhuis, T.S., Winchell, M., Rossing, J., Zollweg, J.A. and Walter, M.F. (1995) SCS Runoff Equation Revisited for Variable-Source Runoff Areas. Journal of Irrigation and Drainage Engineering, 121, 234-238. http://dx.doi.org/10.1061/(ASCE)0733-9437(1995)121:3(234)

[32] Huang, M.B., Gallichand, J., Dong, C.Y., Wang, Z.L. and Shao, M.A. (2007) Use of Moisture Data and Curve Number Method for Estimating Runoff in the Loess Plateau of China. Hydrological Processes, 21, 1471-1481. http://dx.doi.org/10.1002/hyp.6312

[33] Shaw, S.B. and Walter, M.T. (2009) Estimating Storm Runoff Risk Using Bivariate Frequency Analyses of Rainfall and Antecedent Watershed Wetness. Water Resources Research, 45, Article ID: W03404.

[34] Hjelmfelt Jr., A.T., Kramer, L.A. and Burwell, R.E. (1982) Curve Numbers as Random Variables. Proceeding of the International Symposium on Rainfall-Runoff Modeling, Littleton, 18-21 May 1981, 365-373.

[35] Gajbhiye, S., Mishra, S.K. and Pandey, A. (2013) Effects of Seasonal/ Monthly Variation on Runoff Curve Number for Selected Watersheds of Narmada Basin. International Journal of Environmental Sciences, 3, 2034-3046.

[36] USDA-Soil Conservation Service (USDA SCS) (1985) National Engineering Handbook. Section 4. Hydrology. USDASCS, Washington DC.

[37] Chen, C.L. (1982) An Evaluation of the Mathematics and Physical Significance of the Soil Conservation Service Curve Number Procedure for Estimating Runoff volume. Proceeding of the International Symposium on Rainfall-Runoff Modeling, Littleton, 18-21 May 1981, 387-418.

[38] Hawkins, R.H., Ward, T.J., Woodward, D.E. and Van Mullem, J.A. (2010) Continuing Evolution of Rainfall-Runoff and the Curve Number Precedent. Proceedings of the 4th Federal Interagency Hydrologic Modeling Conference, Las Vegas, 27 June-1 July 2010, 1-12.

[39] Yuan, P.T. (1993) Logarithmic Frequency Distribution. Annals of Mathematical Statistics, 4, 30-74. http://dx.doi.org/10.1214/aoms/1177732821

[40] Prasuhn, A. (1992) Fundamentals of Hydraulic Engineering. Oxford University Press, New York.

[41] Woodward, D.E., Van Mullem, J.A., Hawkins, R.H. and Plummer, A. (2010) Curve Number Completion Study. Consultant's Report to USDA, NRCS, Beltsville, $38 \mathrm{p}$.

[42] Arnold, J.G., Muttiah, R.S., Srinivasan, R. and Allen, P.M. (2000) Regional Estimation of Base Flow and Ground Water Recharge in the Upper Mississippi River Basin. Journal of Hydrology, 227, 21-40. http://dx.doi.org/10.1016/S0022-1694(99)00139-0

[43] Nathan, R.J. and McMohan, T.A. (1990) Evaluation of Automated Techniques for Base Flow and Recession Analyses. 
Water Resources Research, 26, 1465-1473. http://dx.doi.org/10.1029/WR026i007p01465

[44] Willmott, C.J., Robeson, S.M. and Matsuura, K. (2012) A Refined Index of Model Performance. International Journal of Climatology, 32, 2088-2094.

[45] Legates, D.R. and McCabe, G.J. (1999) Evaluating the Use of "Goodness-of-Fit" Measures in Hydrologic and Hydroclimatic Model Validation. Water Resources Research, 35, 233-241. http://dx.doi.org/10.1029/1998WR900018 
Scientific Research Publishing (SCIRP) is one of the largest Open Access journal publishers. It is currently publishing more than 200 open access, online, peer-reviewed journals covering a wide range of academic disciplines. SCIRP serves the worldwide academic communities and contributes to the progress and application of science with its publication.

Other selected journals from SCIRP are listed as below. Submit your manuscript to us via either submit@scirp.org or Online Submission Portal.
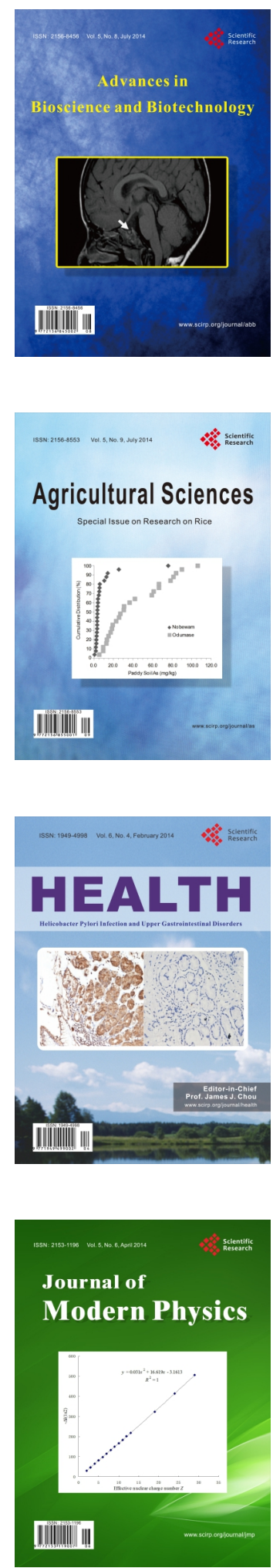
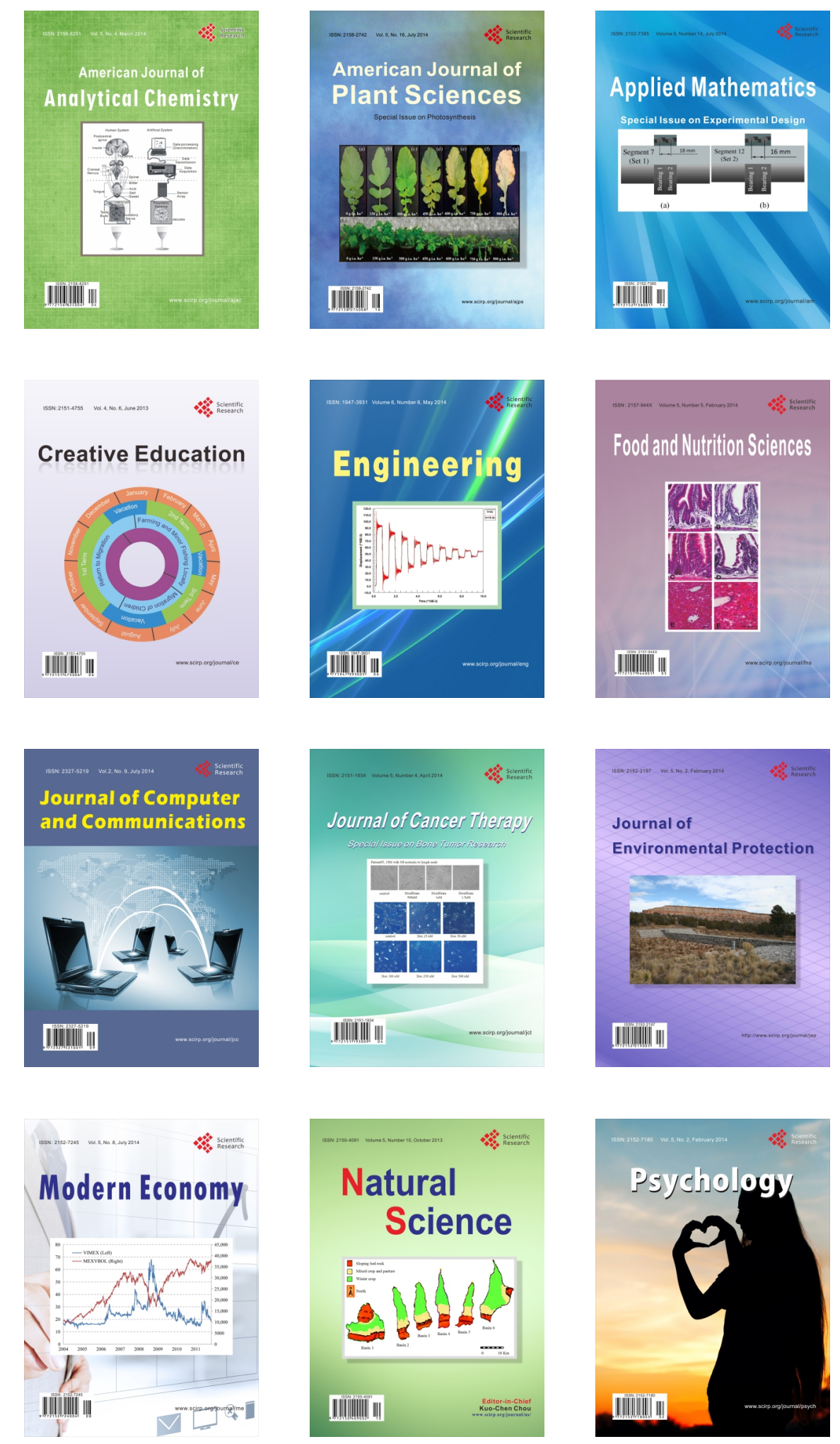